\title{
IS POST-CATARACT MYDRIASIS NECESSARY?
}

\author{
M. TEIMORY, K. DAVEY and I. B. MARSH \\ Liverpool
}

\begin{abstract}
SUMMARY
We report the results of a randomised prospective trial of post-operative cyclopentolate in patients who had uncomplicated endocapsular cataract extraction. We found no significant difference in visual acuity, intraocular lens centration or pupil area achieved after dilatation with tropicamide. There was a marked increase in the incidence of posterior synechiae in the group receiving cyclopentolate (33\% vs. $13 \%)$.
\end{abstract}

There is a wide variation in the use of mydriatics following extracapsular cataract extraction (ECCE), ranging from no mydriasis to several weeks of mydriasis. McEntyre ${ }^{1}$ undertook 'can-opener' ECCE and posterior chamber intraocular lens (IOL) implantation on 294 patients. He compared the effect of routine peripheral iridectomy and post-operative mydriasis on the formation of posterior synechiae. He reported a $32 \%$ incidence of posterior synechiae in those receiving mydriatics and peripheral iridectomy, against $10 \%$ in those having neither. The relative contribution of peripheral iridectomy mydriasis was not examined.

In a recent retrospective study Kearns et $a l^{2}$ reported that post-operative mydriasis was associated with an increase in the formation of posterior synechiae. Rosen $e t$ $a l .{ }^{3}$ have reported a greater incidence of posterior synechiae in endocapsular versus 'can-opener' technique; however, both groups in their study received post-operative mydriasis.

This study examined the effect of post-operative mydriasis on posterior synechiae formation.

\section{PATIENTS AND METHODS}

Sixty patients with cataracts and no other ocular abnormality, who had undergone uncomplicated endocapsular cataract extraction and posterior chamber lens implantation, were randomly allocated on the first postoperative day to one of two groups: mydriatic and control. Both groups used a topical combination of betamethasone and neomycin q.d.s. for 6 weeks. In addition the mydriatic group used cyclopentolate $1 \%$ b.d. for 2 weeks.

Correspondence to: Mr. I. B. Marsh, Ophthalmology Department, Walton Hospital, Rice Lane, Liverpool L9 1AE, UK.
Operative technique involved corneal section, letter box capsulotomy, hydrodissection, nucleus expression and manual irrigation/aspiration of cortex. A one-piece $7 \mathrm{~mm}$ optic IOL (3M17XE) was inserted and dialled as required to obtain centration. The section was closed with interrupted 10-0 monofilament polyamide. Subconjunctival gentamicin $20 \mathrm{mg}$ and betamethasone $4 \mathrm{mg}$ were given at the end of the procedure. The patients were reviewed at 1 and 6 weeks post-operatively. At 6 weeks a single observer (I.B.M.) who was masked to the randomisation carried out full anterior segment examination. Particular attention was paid to the following:

Presence, degree and position of any posterior synechiae. The pupillary dimensions in the horizontal and vertical meridians. These were compared by adjusting the slit length of the Haag Streit 900 slit lamp beam both before and 20 minutes after instillation of 1 drop of $1 \%$ tropicamide.

Intraocular lens centration. This was estimated by assessing IOL edge show against the dilated pupil in retroillumination.

\section{RESULTS}

Both groups were analysed by an unpaired $t$-test for age and sex matching. The mean age of the mydriatic group was 71.4 years (SD12.14 years) and of the controls 72.4 years (SD 8.77 years) $(p=0.8, \mathrm{NS})$. The mydriatic group had 11 (37\%) men, the controls 14 (47\%) ( $p=0.44$, NS). The two groups appeared matched for age and sex.

The following findings were compared by the Wilcoxon rank sum test. The amount of decentration in both groups was small, being $0.167 \mathrm{~mm}$ in the controls and $0.133 \mathrm{~mm}$ in the mydriatic group $(p=0.33$, NS). Although there appeared to be a trend towards a larger pupil in the control group $\left(24.6 \mathrm{~mm}^{2}\right.$ vs. $\left.21.0 \mathrm{~mm}^{2}\right)$ this was not significantly different $(p=0.053)$. The incidence of posterior synechiae in the mydriatic group was $10(33 \%) ; 9$ patients had a single, discrete posterior synechia and 1 patient had two. In the control group, 4 patients (13\%) had a single, discrete posterior synechia. This difference is statistically significant $(p=0.029)$. No patient in either group had pupillary capture of the IOL. 


\section{DISCUSSION}

This study has shown a significantly greater formation of posterior synechiae in patients receiving cyclopentolate after uncomplicated cataract surgery.

The clinical significance of posterior synechiae as reported by McEntyre ${ }^{1}$ is a cosmetic blemish and interference with future pupillary dilation for posterior segment examination and treatment.

A possible explanation for the greater incidence of posterior synechiae in the mydriatic group is the relative immobility of an inflamed iris. Perhaps normal pupillary excursions in the control group break down tentative adhesions.
We have abandoned the routine use of mydriatics following uncomplicated ECCE+IOL.

Key words: Cataract extraction, Mydriasis, Posterior synechiae.

\section{REFERENCES}

1. McEntyre JM. Posterior synechiae in extracapsular cataract extraction with posterior-chamber intraocular lenses. Ann Ophthalmol 1985;17:664-6.

2. Kearns PP, Kaye-Wilson L, Mackintosh GIS. 'Can-opener' extracapsular cataract extraction: are postoperative mydriatics necessary? Eur J Implant Ref Surg 1992;4:15-18.

3. Rosen PH, Twomey JM, Kirkness CM. Endocapsular cataract extraction. Eye 1989;3:672-7. 